Journal of Business and Tourism

Volume 06 Number 01

January - June, 2020

\title{
Training, Performance Appraisal and Compensation Moderating Impact on the Relationship of Employee Engagement and Organizational Citizenship Behavior
}

\author{
Dr. Hazrat Bilal \\ Assistant Professor, Center for Management and Commerce \\ University of Swat, Swat \\ hbilal@uswat.edu.pk \\ Dr. Naveed Farooq \\ Assistant Professor, Institute of Business Studies and Leadership \\ Abdul Wali Khan University, Mardan \\ Naveedfarooq151@gmail.com \\ Muhammad Waseem \\ Assistant Professor, Department of Management Sciences \\ Hazara University, Mansehra \\ mwaseem@hu.edu.pk \\ Sher Ali \\ PhD Scholar, Management Sciences and Engineering \\ College of Economics and Management \\ Three Gorges University, Yichang, China \\ Sherali9404@gmail.com
}

\begin{abstract}
The purpose of this paper is to pinpoint the impact of Employee Engagement on Organizational Citizenship Behavior. It also studies the moderating effect of training, compensation and performance appraisal on EE and $O C B$ connection. A survey design was incorporated to select employees from Universities owned by private sector. The causal relationship was checked by regression and hierarchal multiple regression analysis was applied for the centralized impact of moderating variable on EE and OCB relationship. A total of 281 questionnaires were circulated among respondents and 266 valid responses were received back. On the basis of statistical analysis it was found that employee engagement was a good predictor and has a significant impact on OCB. However, the moderating variables training, compensation and performance appraisal were also having a significant impact on the link of employee engagement and OCB. It is recommended that the managers must focus on employees training, compensation and proper appraisal system to further nourish the citizenship behavior of employee in order to promote the organization objectives. The scope of the present research is limited to private sector universities; therefore, in future a relative study of both private and public
\end{abstract}


sector universities may be carried out by considering both administrative and teaching faculty.

Key Words: Employee Engagement, Organizational Citizenship Behavior, Training, Performance Appraisal, Compensation, Moderating Role

\section{Introduction}

In this modern, dynamic and global era of business, no organization can thrive without people who are highly engaged and dedicated to their jobs in order to meet the expectations set by the organization and boost performance against their rivals. Highly engaged employees plays a vital role in the success of any organisation, as engaged employees are highly competitive, committed to enhancing efficiency and leading the organization to sustainable growth and development.It is obvious, as Kahn (1990) said that engagement is a psychological setting that enables employees of an organization to participate actively in their own and organizational tasks. As a result, engaged employees are positive, accomplishing and getting a work-related state of attention categorized by vigor, absorption and dedication (W. B. Schaufeli, Martinez, Pinto, Salanova, \& Bakker, 2002). On the other hand, reference to field of psychology and organizational behavior the job performance is a multidimensional concept and can be studied from many perspective but according to Chaudhry and Usman (2011) job performance can be best represented by Organizational Citizenship Behavior (OCB). According to Arvey and Murphy (1998) OCB is the additional job proficiency which shapes the organizational, social and psychological environment for accomplishing organization goals and hence taken as a dependent variable in the current study.

Extra ordinary job performance in organizations is expected to be performed by highly engaged employees compared to those employees who are not highly engaged. Employees who are highly engaged are expected to work at a higher level as well as to go beyond formal jobs obligations. Studies have confirmed that behavior that goes beyond the prescribed jobs obligations; improves employee performance, hence increasing individual productivity; (Farh, Zhong, \& Organ, 2004; Podsakoff, MacKenzie, Paine, \& Bachrach, 2000). The EE-OCB link has been checked in developed countries with the help of different EE models and performance domains but in Pakistan, the research studies have measured the relationship of employee engagement with other variables such as Task Performance (Bilal, 2017; Rasheed, Khan, \& Ramzan, 2013), Contextual Performance (Bilal, Shah, Yasir, \& Mateen, 2015), Counterproductive Behavior (Bilal, Farooq, \& Hayat, 2019), but the relationship of EE with OCB in teaching faculty of private sector universities has so far remained unexplored. Several situational factors were used to check the moderating consequence on the link between EE and OCB, but none of the studies measured this relationship while introducing several situational factors, such as training, performance assessment and compensation, as moderating 
variables. Therefore, this study is an effort to explore and measure the moderating impact of training, compensation and performance appraisal on the association of EE and OCB.

\section{Literature}

\section{Employee Engagement}

Employee engagement is a key factor in the progress of any organisation, as engaged employees are highly productive, committed to improving performance, reducing turnover and leading the organization to sustainable growth and development. For instance, according to Schaufeli, Salanova, Gonza, \& Bakker (2002) engagement is an optimistic, accomplishing, job-associated state of attention regarded as by means of vigor, absorption and dedication. Vigor is seen as a high degree of energy and mental endurance while working, ability to put effort in one's work and determination in the face of difficulties as well. Dedication is distinguished by a sense of purpose, loyalty, excitement, enthusiasm, passion, pride and the challenge of carrying out a particular task. Absorption is characterized by focus, desire, and captivation, and happily immersed in one's work where time passes rapidly and one has difficulty separating from job. In overall, engaged employees have an intellect of spirited and effective affiliation with their job.

An engaged employee is familiar with the organizational environment and works with his or her companions to expand performance in the workplace for the benefit of the organization. (Robinson, Perryman, \& Hayday, 2004). Competence, commitment and contribution are the three key qualities of the employee, leading the organization to success. But the success of an organization depends not only on the competence and cognitive abilities of workers, but also on the way in which workers react sensitively to their work and organization. Employee engagement is therefore a key issue in management and human resource development, as research has argued that engaged employees are more motivated by impartial treatment, appreciation and opportunities for professional development than by monetary incentives and extrinsic motivations. (Bhatt, 2012)

\section{Organizational Citizenship Behavior}

Earlier, Fredrick Taylor (1919) proposed a program to increase efficiency of organization by finding the quickest, most effective and least fatiguing production methods. He studied the notion of increasing organizational success through employee performance and completely ignored the employee's voluntary actions consist of positive and productive social behaviors, including the ability to complete a mission without contemplating time or personal difficulty or assisting other colleagues with no hopes of potential benefits(Rose, 2012; Shafritz, Hyde, \& Parkes, 2004). However, Organ (1988), states there is more to employee performance than simply carrying out formal job duties. Many tasks are performed that do not form part of the job descriptions of the employees, not compensated by any structured processes and yet contribute positively to the organization, and such activities are called organizational citizenship behaviors (Smith, 
Organ, \& Near, 1983). OCB has an effect on both organizational efficiency and service quality so managers should always aim to enhance OCB efficacy of their employees (González \& Garazo, 2006). OCB is the additional workload voluntarily undertaken by individuals and the organization would definitely like employees to demonstrate such behaviors. (Kreitner \& Kinicki, 2004)

Organizational Citizenship Behavior is a discretionary and voluntarily behavior where one goes beyond his / her described duties and often wants to make a positive contribution to the success of his / her organization. It is an extra-role behavior consisting of behavior that goes beyond the necessity of a job and ultimately has a positive effect on overall organizational performance(Organ, 1988). According to Arvey and Murphy (1998)OCB is the additional job proficiency which shapes the organizational, social and psychological environment for accomplishing organization goals. These are acts that are not really part of the obligations of the employees and are therefore not officially compensated but which continue to make a positive contribution to the organization. (Bettencourt, Gwinner, \& Meuter, 2001). OCB has several definitions (Dalal \& Carpenter, 2018; Graham, 1991; Podsakoff, MacKenzie, \& Podsakoff, 2018), but as Universities are service oriented organizations, therefore the Bettencourt et al. (2001) service oriented definition of OCB is adopted here, which is an employee loyalty, participation and service delivery(Bettencourt et al., 2001).

The connection between employee engagement and other job related outcome such as task performance(Shantz, Alfes, Truss, \& Soane, 2013), contextual performance (Bilal et al., 2015)and counterproductive behavior (Bilal, Farooq, \& Hayat)are well researched.But many of the studies have also showed a positive link between EE and OCB in different setup other than universities(Bilal, Mateen, \& Sohail, 2017; Rurkkhum \& Bartlett, 2012; Saradha \& Patrick, 2011).These positive relationships between EE and other constructs mean that employees who are highly engaged will respond favorably to each other and to the organization by returning benefits, either with indifference or with hostility. The exchange of voluntary reactions between employees is motivated by the desired benefits and usually results from a mutually beneficial interaction between the two parties. (Blau, 1968). Therefore, on the basis of this social exchange theory of (Blau, 1968), we proposes of first hypothesis as:

H1: OCB is predicted by employee engagement.

\section{Moderating Variables}

Marwat, Qureshi, and Ramay (2009)argued that in order to achieve high progress, the organisation must focus on training, employee retention, appraisal and incentives in order to increase employee overall performance and achieve organizational objectives. Training improves the skills required and leads to the advancement of the employee as well as the overall performance of the company (Cloutier, Felusiak, Hill, \& Pemberton-Jones, 2015). The provision of training to employees effectively improves the efficiency of employees (Luthans \& Stajkovic, 2000) and such acts of organization can be seen by employees as 
their organizational support and hence they go an extra mile for achieving organizational objectives (Ahmad, 2011).Ichniowski and Shaw (2003)sayCompensation and incentive programs subject to flexible design and new skills training have a positive effect on the efficiency of employees. If an employee is sufficiently compensated for his work, his behavior will change positively (Gupta, Singh, No, \& Hostel, 2010).Likewise, if employee performance is adequately measured for the purpose of measuring and evaluating employee performance, promote a meaningful improvement in employee actions towards achieving organizational goals (Yeh, 2011).

Beer, Spector, Lawrence, Mills, and Walton (1984)stated that training, performance appraisal and compensation are situational factors. Situational factors include the characteristics of the workforce, the unions and all other factors that have also been identified in the 8-box model. Whereas training, performance appraisal and compensation are core human resource practices (HRMs) and included as integral HR practices in the 8box HRM model. (Boselie, 2010) and consequently, on the basis of this, we have taken these three HR practices as moderating variables. Therefore, we have developed the following hypotheses.

H2: The employee engagement and OCB association is moderated by training

H3: The employee engagement and OCB association is moderated by compensation

H4: Employee engagement and OCB relationship is moderated by performance appraisal.

\section{Objectives}

This study's objectives are dual. The first aim is to examine the EE-OCB relationship and OCB prediction through EE. The second objective is to determine and measure the moderating impact of training, compensation and performance relationship on the link of EE and OCB.

\section{Methodology}

\section{Population and Sampling}

TheKrejcie and Morgan (1970)) formula was used to determine the sample size of 1005 people working at a university owned by the private sector in Khyber Pakhtunkhwa. After that, the sample was calculated as 281. A total of 281 self-governing questionnaires were distributed among teachers working in private universities. Data were collected randomly and a total of 266 (94 per cent) questionnaires were returned.

\section{Measures}


For measuring engagement of employees The Utrecht Work Engagement Scale (UWES) consisting of seventeen questions comprising of vigor, dedication and absorption was adapt from W. Schaufeli and Bakker (2003). The OCB was measured with a service oriented citizenship behavior scale embraced from (Bettencourt et al., 2001), whereas training, compensation and performance appraisal questionnaire was adopted from (Singh, 2004). All the Scales were calculated a Cronbach's alpha value more than the acceptable range of 0.70 .

\section{Data Analysis}

\section{Descriptive Statistics of Variables}

Table 1 below displays that the highest average is 3.99 of the engagement, while the lowest average of 3.19 is calculated from performance appraisal this is the moderating variable. However, the second largest average of 3.82 pertains to $\mathrm{OCB}$, which is the criterion variable in this study. It shows that the teaching faculty believes that a high level of engaged employees generates the maximum level of yield, although they have a weak belief in the performance appraisal as moderator and have an impact on the OCB of the teaching faculty of private universities.

\section{Table 1: Descriptive Statistics}

\begin{tabular}{llllll}
\hline & N & Min & Max & Mean & Std. Deviation \\
\hline Employee Engagement & 266 & 2.00 & 5.00 & 3.993 & .519 \\
OCB & 266 & 1.81 & 4.88 & 3.822 & .595 \\
Training & 266 & 1.00 & 5.00 & 3.463 & .874 \\
Incentives & 266 & 1.00 & 5.00 & 3.458 & .882 \\
Performance Appraisal & 266 & 1.00 & 5.00 & 3.192 & .907 \\
\hline
\end{tabular}

\section{Hypothesis Testing}

The findings of the Pearson correlation in Table 2 indicate positive correlation among all variables.

Table 2: Correlations between Independent and Dependent variables

\begin{tabular}{lcc}
\hline Variables & 1 & 2 \\
\hline $1 . \mathrm{EE}$ & 1 & .45 \\
$2 . \mathrm{OCB}$ & & 1 \\
\hline
\end{tabular}

Table 3 below shows the ANOVA test findings of the regression analysisdetermine the significance of $\mathrm{F}>0.05$ for the EE-OCB prediction association. This result underpins our first hypothesis by confirming that the employee engagement score significantly predicts the OCB.A constant value of Intercept 1.34 and a slope of 0.49 of engagement regression line symbolizethat one unit rise in engagement can significantly predict a 0.490 units increase in OCB.

\section{Table 3: $\quad$ ANOVA and Coefficients}




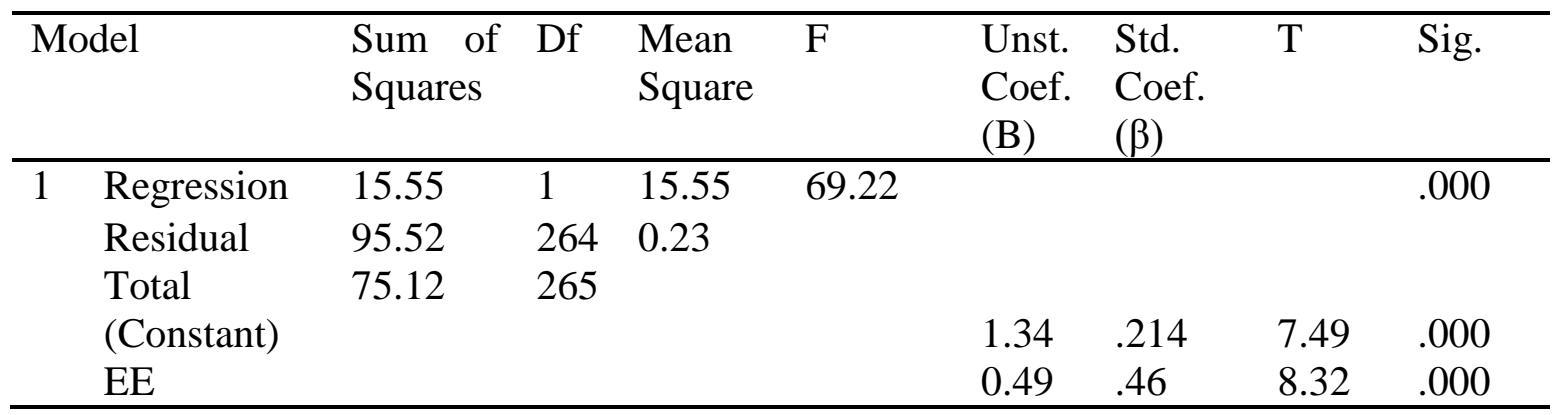

The Model Summarypresented in Table 4 reveals that an $\mathrm{R}^{2}$ of 0.46 specifies that 46 per cent of the OCB variance could be counted on the employee engagement score and hence confirms our first hypothesis.

Table 4: Model Summary

\begin{tabular}{llccc}
\hline Model & $\mathrm{R}$ & $\mathrm{R}$ Square & Adjusted R Square & Std. Error of the Estimate \\
\hline 1 & .46 & .22 & .21 & .47 \\
\hline
\end{tabular}

a. Predictors: (Constant), Employee Engagement

Table 5 captures the results of moderation of training, compensation and performance appraisal on the linkbetween EE and OCB. The results shown in table 5confirms that coefficients of the interaction term EE*TRNG, EE*COMP and EE*PA are significant, which indicates that training moderates the relationship between EE and OCB $(\beta=.10$, $\mathrm{p}<.01)$, compensation moderates similar relationship between $\mathrm{EE}^{*} \mathrm{OCB}(\beta=.15, \mathrm{p}<.01)$ and likewise performance appraisal also moderates the connection between EE*OCB. Hence the results of our analysis confirms hypothesis 2,3 and 4 respectively.

Table 5 Moderating Analysis

\begin{tabular}{|c|c|c|c|c|c|c|}
\hline \multicolumn{2}{|r|}{ Variable } & \begin{tabular}{|l} 
Stand. \\
Coeff.
\end{tabular} & $T$ & $\overline{\mathbf{R}^{2}}$ & $\mathbf{F}$ & Sig. \\
\hline \multicolumn{7}{|c|}{ Hypothesis 2 Results } \\
\hline $\begin{array}{l}\text { Model } \\
1\end{array}$ & $\mathrm{EE}$ & 0.46 & 9.32 & .207 & 69.22 & .000 \\
\hline Model & $\mathrm{EE}$ & 0.42 & 5.93 & & & \\
\hline 2 & TRNG & 0.07 & 0.91 & 0.210 & 34.89 & .000 \\
\hline Model & $\mathrm{EE}$ & 0.37 & 5.27 & & & \\
\hline 3 & TRNG & 0.07 & 0.87 & 0.220 & 24.69 & .000 \\
\hline & Interaction Term EE*TRNG & 0.10 & 1.86 & & & \\
\hline \multicolumn{7}{|c|}{ Hypothesis 3 Results } \\
\hline
\end{tabular}




\begin{tabular}{lllllll}
\hline Model & EE & 0.46 & 8.34 & 0.207 & 69.22 & .000 \\
$\mathbf{1}$ & & & & & & \\
Model & EE & 0.38 & 5.83 & & & \\
$\mathbf{2}$ & COMP & 0.12 & 1.69 & 0.216 & 36.29 & .000 \\
Model & EE & 0.34 & 4.89 & & & \\
$\mathbf{3}$ & COMP & 0.12 & 1.78 & 0.236 & 27.06 & .000 \\
$\quad$ & Interaction Term EE*COMP & 0.15 & 2.64 & & & \\
Hypothesis 4 Results & & & & & \\
\hline Model & EE & 0.46 & 8.35 & 0.207 & 69.22 & .000 \\
$\mathbf{1}$ & & 0.39 & 5.83 & & & \\
Model & EE & & & 0.215 & 36.13 & .000 \\
$\mathbf{2}$ & & 0.1 & 1.69 & & & \\
Model & EA & 0.34 & 4.85 & & & \\
$\mathbf{3}$ & PA & 0.12 & 1.81 & 0.238 & 27.34 & .000 \\
& Interaction Term EE*PA & 0.16 & 2.81 & & & \\
\hline
\end{tabular}

Dependent Variable: OCB = Organizational Citizenship Behavior

$\mathrm{EE}=$ Employee Engagement $\quad \mathrm{TRNG}=$ Training, $\mathrm{COMP}=$ Compensation, $\mathrm{PA}=$

Performance Appraisal

\section{Discussions}

The results indicated a significant positive relationship $(\mathrm{r}=.45, \mathrm{p}<.01)$ between employee engagement (Independent variable) and OCB (Dependent variable). Similar results were found by Babcock-Roberson and Strickland (2010)where employee engagement was significantly positively correlated with OCB represented by $(r=.41, p$ $<.01)$. Furthermore, our findings also supported the results of Rich, Lepine, and Crawford (2010)who have empirically validated and concluded positive and significant relationship between EE and OCB

Employees' score on EE significantly predicts OCB was the first hypothesis of this study. It was confirmed that EE is the predictor of OCB. This result is in compliance with the outcomes of Dalal, Brummel, Wee, and Thomas (2008). and (Dalal, Baysinger, Brummel, \& LeBreton, 2012)studies which supports that employee engagement significantly predict OCB . Dalal et al., (2012) accounted $\beta=.30, p<.01, R^{2}=.06$, predicted that employee engagement accounted for $6 \%$ variance inOCB .BabcockRoberson and Strickland (2010)alsoconducted regression analysis for employee engagement and Organizational Citizenship Behavior. They found that EE (Independent variable) significantly predict OCB (Dependent Variable) with $\beta=.41, p<.01, R^{2}=.16$, stating that EE accounted $16 \%$ variance in, which is lower than the variance calculated for the current study. This low R square value might be due to change in culture and environment as Babcock-Roberson study was conducted in developed country (California, USA). Besides this their sample was consist of the undergraduate students 
who studied only Psychology, while the sample of the current study were employees of the University teaching to different disciplines

Training moderates the association between EE and organizational citizenship behavior, was the third hypothesis of this study. The results of general linear model analysis confirmed that training significantly predicts the value of (Dependent Variable) and the interaction term EE and Training. The previous studies could not establish the moderating role of benefits of training on the connection of EE and OCB. According to Islam, Khan, Aamir, Ahmed, and Ahmad (2012) benefits of training ( $\beta=.15, \mathrm{t}=4.79$, $p<.001$ ) has a variance less than 5\% and thus their analysis did not supported our hypothesis that moderating role of employees perception of training significantly predict the EE-OCB link. Firstly this might be because of difference in scales used by present research. Secondly this variation of results might be because Islam et al (2012) collected data from mix of five different large organizations including three public organizations (petroleum, chemical and agriculture) and two private organizations (manufacturing and services), whereas the present study have used only service oriented organizations private universities.

Compensation moderates the relationship between EE and OCB, was the third hypothesis of this study. The results confirmed that compensation significantly moderates the association between EE and OCB. Similarly, performance appraisal moderates the association between employee engagement and OCB, was the fourth hypothesis of this study. The results of general linear model analysis confirmed that performance appraisal significantly moderated the association between EE and OCB.

\section{Conclusion}

This research was conducted to describe the relationship and effect of EE and OCB on the basis of Social Exchange Theory. Engagement was used to improve the citizenship behavior of employees. It was assumed and concluded that employees who are engaged in their job often go an extra mile for performing a particular job and hence confirming Social Exchange Theory. To further strengthen the relationship between EE and OCB, training, performance appraisal and compensation were used as moderators. The results revealed that the all the three moderating variables further strengthen the relationship between EE and OCB.

\section{Implications and Limitations}

This research adds to current knowledge by developing a theoretical model based on gaps in literature. The results of this study not only validate the findings of previous studies on the impact of EE on OCB in the teaching faculty, but also have the potential to fill the gap identified in previous studies. Many of the previous studies have focused on the linear relationship between EE and performance, but the moderating part of training, performance assessment and compensation is overlooked. 
This research also has significant practical implications. Engaged employees are more motivated and perform beyond their personal abilities and comparatively work more efficiently then disengaged employees(Kahn \& Heaphy, 2013; Lockwood, 2007). Soengaged employees are more motivated and are more productive than their disengaged counterparts. They work more efficiently and produce maximum productivity. Therefore, the managers should always focus on such employees and shall provide them proper training, appraise their performance honestly and paid them attractive compensation and incentive in order to achieve the organizational objectives.

The primary limitation of this study is its cross-sectional structure, which reduces the causal relationship. Potential studies may draw conclusions from a longitudinal study that will explore how EE affects citizenship behaviour. Second, this survey only gathered data from a limited sample size; in future studies, data from a larger sample across Pakistan should be collected in order to address the issue of generalizability. Third, data were obtained from private sector universities; therefore, for the validity and generalizability of the results, a comparative analysis could be carried out in future for universities in both the private and public sectors, taking into account both administrative and teaching staff.

\section{References}

Ahmad, K. Z. (2011). The association between training and organizational citizenship behavior in the digital world. Communications of the IBIMA.

Arvey, R. D., \& Murphy, K. R. (1998). Performance evaluation in work settings. Annual review of psychology, 49(1), 141-168.

Babcock-Roberson, M. E., \& Strickland, O. J. (2010). The relationship between charismatic leadership, work engagement, and organizational citizenship behaviors. the Journal of Psychology, 144(3), 313-326.

Beer, M., Spector, B. A., Lawrence, P. R., Mills, D. Q., \& Walton, R. E. (1984). Managing human assets: Simon and Schuster.

Bettencourt, L. A., Gwinner, K. P., \& Meuter, M. L. (2001). A comparison of attitude, personality, and knowledge predictors of service-oriented organizational citizenship behaviors. Journal of applied psychology, 86(1), 29.

Bhatt, K. (2012). Employee Engagement: A Tool to Achieve Sustainable Growth"-A Case Study Of GNFC. International Journal of Research in Management, Economics and Commerce, 2(6), 92-105.

Bilal, H. (2017). The moderating role of HR practices on the association of employee engagement and job performance. Hazara University, Mansehra.

Bilal, H., Farooq, N., \& Hayat, K. Empirically Investigating the Impact of Employee Engagement on Counterproductive Work Behavior of Academic Staff. 
Bilal, H., Farooq, N., \& Hayat, K. (2019). Empirically Investigating the Impact of Employee Engagement on Counterproductive Work Behavior of Academic Staff. Global Regional Review, 4(1), 8.

Bilal, H., Mateen, A., \& Sohail, M. (2017). The Role of Engagement in Relationship to Organization Citizenship Behavior in Pakistan. Journal of Managerial Sciences, $X I(4), 12$.

Bilal, H., Shah, B., Yasir, M., \& Mateen, A. (2015). Employee engagement and contextual performance of teaching faculty of private universities. Journal of Managerial Sciences Volume IX Number, 1, 82.

Blau, P. M. (1968). Social exchange. International encyclopedia of the social sciences, 7, $452-457$.

Boselie, P. (2010). Strategic human resource management: A balanced approach: Tata McGraw-Hill Education.

Chaudhry, A., \& Usman, A. (2011). An investigation of the relationship between employees' emotional intelligence and performance. African Journal of Business Management, 5(9), 3556-3562.

Cloutier, O., Felusiak, L., Hill, C., \& Pemberton-Jones, E. J. (2015). The Importance of Developing Strategies for Employee Retention. Journal of Leadership, Accountability \& Ethics, 12(2).

Dalal, R. S., Baysinger, M., Brummel, B. J., \& LeBreton, J. M. (2012). The relative importance of employee engagement, other job attitudes, and trait affect as predictors of job performance. Journal of Applied Social Psychology, 42, E295E325.

Dalal, R. S., Brummel, B. J., Wee, S., \& Thomas, L. L. (2008). Defining employee engagement for productive research and practice. Industrial and Organizational Psychology, 1(1), 52-55.

Dalal, R. S., \& Carpenter, N. C. (2018). The other side of the coin? Similarities and differences between organizational citizenship behavior and counterproductive work behavior. The Oxford handbook of organizational citizenship behavior, 6990.

Farh, J.-L., Zhong, C.-B., \& Organ, D. W. (2004). Organizational citizenship behavior in the People's Republic of China. Organization science, 15(2), 241-253.

González, J. V., \& Garazo, T. G. (2006). Structural relationships between organizational service orientation, contact employee job satisfaction and citizenship behavior. International journal of service industry management.

Graham, J. W. (1991). An essay on organizational citizenship behavior. Employee responsibilities and rights journal, 4(4), 249-270.

Gupta, V., Singh, S., No, R., \& Hostel, F. (2010). Developing a set of high performance $H R M$ practices and exploring its relationship with $O C B$ and organizational justice. Paper presented at the Proceedings of the 2010 meeting of the Southern Management Association. 
Ichniowski, C., \& Shaw, K. (2003). Beyond incentive pay: Insiders' estimates of the value of complementary human resource management practices. Journal of Economic Perspectives, 17(1), 155-180.

Islam, T., Khan, S., Aamir, M., Ahmed, I., \& Ahmad, U. KU and Shaukat., M. Z (2012): Moderating role of HRD practices between employees' engagement and citizenship behaviour. Middle-East Journal of Scientific Research, 12(5), 589597.

Kahn, W. A. (1990). Psychological conditions of personal engagement and disengagement at work. Academy of Management Journal, 33(4), 692-724.

Kahn, W. A., \& Heaphy, E. D. (2013). Relational contexts of personal engagement at work Employee engagement in theory and practice (pp. 96-110): Routledge.

Kreitner, R., \& Kinicki, A. (2004). Comportamento organizzativo: Apogeo editore.

Krejcie, R. V., \& Morgan, D. W. (1970). Determining sample size for research activities. Educational and psychological measurement, 30(3), 607-610.

Lockwood, N. R. (2007). Leveraging employee engagement for competitive advantage. Society for Human Resource Management Research Quarterly, 1(1), 1-12.

Luthans, F., \& Stajkovic, A. D. (2000). Provide recognition for performance improvement. Handbook of principles of organizational behavior, 166-180.

Marwat, A., Qureshi, M., \& Ramay, M. (2009). Impact of Human Resource Management (HRM) Practices on Employees Performance: A Case of Pakistani Telecom Sector. Unpublished Paper.

Organ, D. W. (1988). Organizational citizenship behavior: The good soldier syndrome: Lexington Books/DC Heath and Com.

Podsakoff, P. M., MacKenzie, S. B., Paine, J. B., \& Bachrach, D. G. (2000).

Organizational citizenship behaviors: A critical review of the theoretical and empirical literature and suggestions for future research. Journal of management, 26(3), 513-563.

Podsakoff, P. M., MacKenzie, S. B., \& Podsakoff, N. P. (2018). The Oxford handbook of organizational citizenship behavior: Oxford University Press.

Rasheed, A., Khan, S., \& Ramzan, M. (2013). Antecedents and consequences of employee engagement: The case of Pakistan. Journal of Business Studies Quarterly, 4(4), 183.

Rich, B. L., Lepine, J. A., \& Crawford, E. R. (2010). Job engagement: Antecedents and effects on job performance. Academy of Management Journal, 53(3), 617-635.

Robinson, D., Perryman, S., \& Hayday, S. (2004). The drivers of employee engagement. Report-Institute for Employment Studies.

Rose, K. J. (2012). Organizational citizenship behaviors in higher education: Examining the relationships between behaviors and performance outcomes for individuals and institutions. 
Rurkkhum, S., \& Bartlett, K. R. (2012). The relationship between employee engagement and organizational citizenship behaviour in Thailand. Human Resource Development International, 15(2), 157-174.

Saradha, H., \& Patrick, H. A. (2011). Employee engagement in relation to organizational citizenship behavior in information technology organizations. Journal of Marketing and Management, 2(2), 74-90.

Schaufeli, W., \& Bakker, A. (2003). UWES-Utrecht work engagement scale: test manual. Unpublished Manuscript: Department of Psychology, Utrecht University, 8.

Schaufeli, W. B., Martinez, I. M., Pinto, A. M., Salanova, M., \& Bakker, A. B. (2002). Burnout and engagement in university students: A cross-national study. Journal of cross-cultural psychology, 33(5), 464-481.

Shafritz, J. M., Hyde, A. C., \& Parkes, S. (2004). Classics ofPublic Administration. Belmont, CA: Wadsworth/Thomson.

Shantz, A., Alfes, K., Truss, C., \& Soane, E. (2013). The role of employee engagement in the relationship between job design and task performance, citizenship and deviant behaviours. The International Journal of Human Resource Management, 24(13), 2608-2627.

Singh, K. (2004). Impact of HR practices on perceived firm performance in India. Asia Pacific Journal of Human Resources, 42(3), 301-317.

Smith, C., Organ, D. W., \& Near, J. P. (1983). Organizational citizenship behavior: Its nature and antecedents. Journal of applied psychology, 68(4), 653.

Taylor, F. W. (1919). The principles of scientific management: Harper \& brothers.

Yeh, S.-P. (2011). The effects of fairness perception of performance appraisal on psychological contract and organizational citizenship behavior. Journal of Information and Optimization Sciences, 32(3), 685-696. 